\title{
AVALIAÇÃO DE UM SERVIÇO DE ROTINA (VACINAÇÃO ANTI-RÁBICA) NO CENTRO DE SAÚDE DE LONDRINA, PARANÁ, BRASIL
}

\author{
Nilton L. TORNERO* \\ Kiko K. SHIBAYAMA *
}

RSPU-B/230

\begin{abstract}
TORNERo, N. L. \& ShIBAyAma, K. K. - Avaliação de um serviço de rotina (vacinação anti-rábica) no Centro de Saúde de Londrina, Paraná. Rev. Saúde públ., S. Paulo, 8:359-67, 1974.
\end{abstract}

RESUMO: Discute-se a importância de uma análise continua das informações obtidas rotineiramente em serviços de saúde, a fim de que reajustes necessários para aumentar a eficiência sejam tomados na época oportuna e para que essas informagões possam ser usadas em planejamentos científicos. Tomou-se como exemplo específico a avaliação de um serviço de vacinação anti-rábica em um Centro de Saúde sede de um distrito sanitário. A populacão caracterizada foi aquela que procurou o serviço na época do estudo (junho de 1969 a abril de 1973). Foi analisada a influência da urbanização e da distância em quilômetros da cidade sede sobre a procura do serviço e feitas algumas consideracões sobre o esquema de vacinação anti-rábica usado. Sempre que possivel foram comparados os dados obtidos com aqueles de outros locais, concluindo que de um modo geral as diferenças encontradas não são significativas.

UNITERMos: Centro de Saúde*; Serviço de rotina (avaliação)*; Sistema de informação sanitária*.

\section{I N T RODU C $\mathrm{AO}$}

De um modo geral os locais que oferecem serviços de saúde à população possuem registros onde são anotados alguns dados referentes às atividades desenvolvidas consideradas mais importantes.

Alderson 1 (1974) definiu que "a principal função de um sistema de informação sanitária é indicar, por meio de uma análise contínua da situação e do rendimento dos serviços sanitários, a ação ou os reajustes necessários para alcançar objetivos estabelecidos".
Sabemos, por outro lado, que esse sistema de registro freqüentemente é incompleto, não obedecendo a normas bem definidas de execução.

Deste modo a falta de dados adequados sobre os problemas de saúde influi marcadamente quando se deseja um planejamento científico em saúde. A falta desses dados, ao lado de outros igualmente importantes, é reponsável pelo planejamento pragmático que se observa na maioria dos países em desenvolvimento ${ }^{6}$.

* Do Departamento de Medicina Geral e Saúde Comunitária do Centro de Ciências da Saúde da Universidade Estadual de Londrina, Paraná, Brasil 
TORNERO, N. L. \& SHIBAYAMA, K. K. - Avaliação de um serviço de rotina (vacinação anti-rábica) no Centro de Saúde de Londrina, Paraná, Brasil. Rev. Saúde públ., S. Paulo, $8: 359-67,1974$.

No presente trabalho estudamos especificamente um desses registros, ou seja, os dados constantes no Centro de Saúde de Londrina sobre vacinação anti-rábica. Isto porque Londrina é sede do $14 .^{\circ}$ Distrito Sanitário do Estado do Paraná, o qual compreende 20 municípios ${ }^{10}$. Procuramos mostrar que esses dados, mesmo incompletos, podem ser úteis em uma avaliação preliminar do problema e também servir para uma melhor caracterização do Centro de Saúde quanto à polarização que exerce na área sob sua jurisdição administrativa.

Trabalho realizado em Ribeirão Preto ${ }^{9}$, que abrange o período de 1960 a 1969 , ocupa-se principalmente em caracterizar a população que procurou o serviço. 0 trabalho realizado em São Paulo ${ }^{11}$, de 1966 a 1967, consistiu em uma colheita planejada de informaçōes, na qual os autores puderam conhecer a verdadeira demanda. $\mathrm{Na}$ medida do possivel comparamos nossos achados com os desses trabalhos.

\section{MATERIAL E METODOS}

0 livro de registro do Centro de Saúde, que serviu de fonte de dados, existe desde junho de 1969, não tendo sido analisado em nenhuma outra ocasião, servindo apenas para preencher uma necessidade burocrática. Nele estão anotados os dados de pessoas consideradas expostas ao vírus rábico e, portanto, foi indicada a vacinação respectiva. É importante ter esse fato em mente, quando se analisa os dados, pois as pessoas que procuraram o serviço e não foram consideradas expostas (e portanto não lhes foi indicada a vacinação) não foram anotadas em lugar algum, limitando assim, algumas de nossas conclusões.

Os dados rotineiramente anotados para cada pessoa são: nome, idade, procedência, data do início da vacinação e número de doses de vacina prescritas. Excetuando o primeiro dado (nome) os de- mais constituem material do presente estudo. Entre junho de 1969 e abril de 1973 foram analisados 1.262 casos, constituindo a totalidade dos casos anotados no referido período, os quais foram anotados em fichas.

Adotou-se o termo genérico de "dados não especificados" àqueles ausentes ou sujeitos a dúvidas de interpretação. $\mathrm{Na}$ leitura das tabelas esses dados foram excluídos para simplificação de análise.

A vacina usada é a do tipo Fuenzalida modificada, preparada no Instituto de Pesquisas Biológicas de Porto Alegre. De todos os municípios do $144^{\circ}$ Distrito Sanitário, somente o Centro de Saúde de Londrina possui a vacina. Assim, se um município a solicitasse, a remessa era anotada no livro, constanto o nome da pessoa que dela faria uso, obedecendo assim as normas rotineiras de registro. Logo, estima-se que todos os casos considerados expostos, que procuraram assistência dentro da área, foram anotados.

\section{RE S U L T D O S}

Os resultados estão apresentados nas Figuras 1, 2 e 3 e nas Tabelas 1 a 5 .

\section{D I S C U S S A O}

$\mathrm{Na}$ Figura 1 vê-se a distribuição das freqüências de todos os casos, no período estudado. De maneira geral nota-se uma variação cíclica, composta por aumentos na frequiência, seguidos por declínios, muitas vezes observando-se essas variações de mês para mês. Nota-se um grande declínio dà frequêencia a partir de outubro de 1972. Os picos tendem a ocorrer nos meses de abril (excetuando-se 1973, por falta de maiores dados) e agosto, sendo que tais frequiências estão sempre acima das médias para cada ano, excetuando-se 1973, de todo o período estudado. As menores freqüências, por outro lado, 
TORNERO, N. L. \& SHIBAYAMA, K. K. - Avalıação de um serviço de rotina (vacinação anti-rábica) no Centro de Saúde de Londrina, Paraná, Brasil. Rev. Saúde públ., S. Paulo, $8: 359-67,1974$.

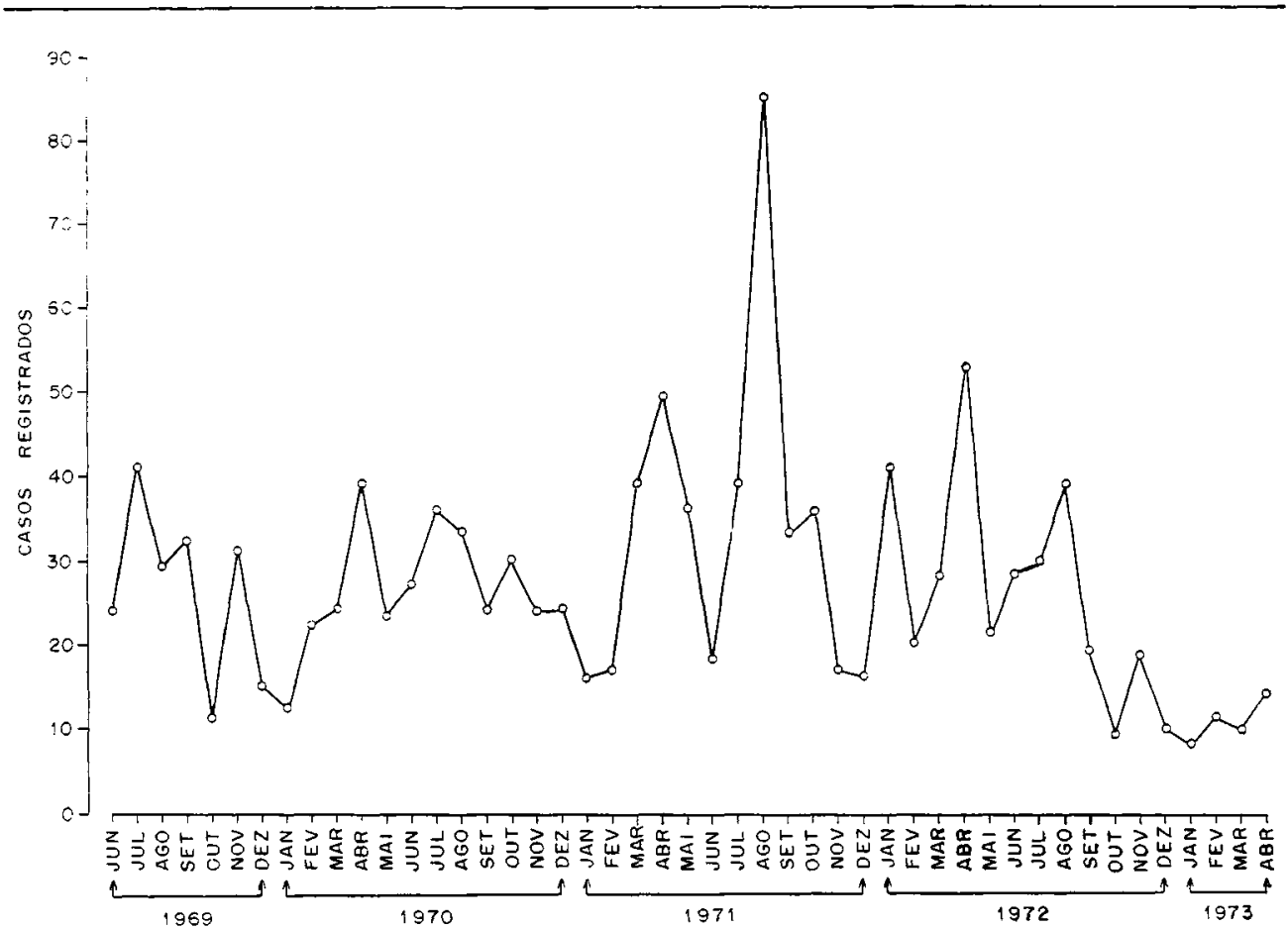

Fig. 1 - Distribuição mensal dos casos registrados no Centro de Saúde de Londrina entre junho de 1969 e abril de 1973, das pessoas consideradas expostas ao vírus rábico e nas quais foi indicada a vacinação anti-rábica.

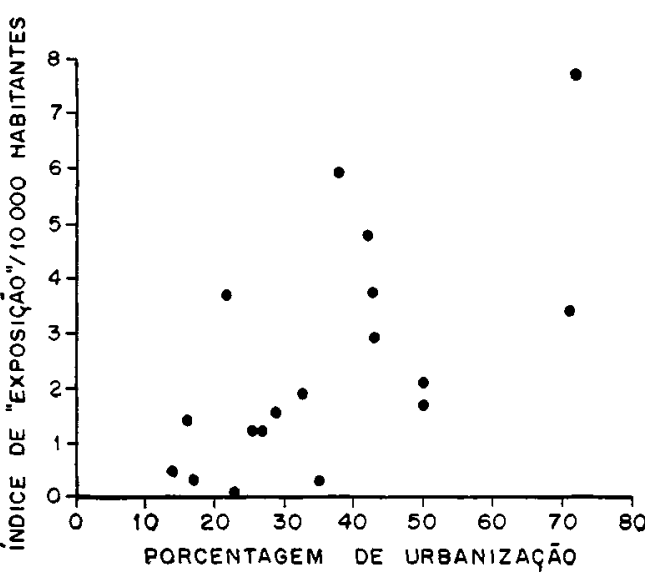

Fig. 2 - Relação entre o indice de "exposiçāo" e a porcentagem de urbanização* dos municípios de onde vieram as pessoas consideradas expostas ao virus rábico e nas quals foi indicada a vacinação anti-rábica.

* Fonte: Fundação IBGE ².

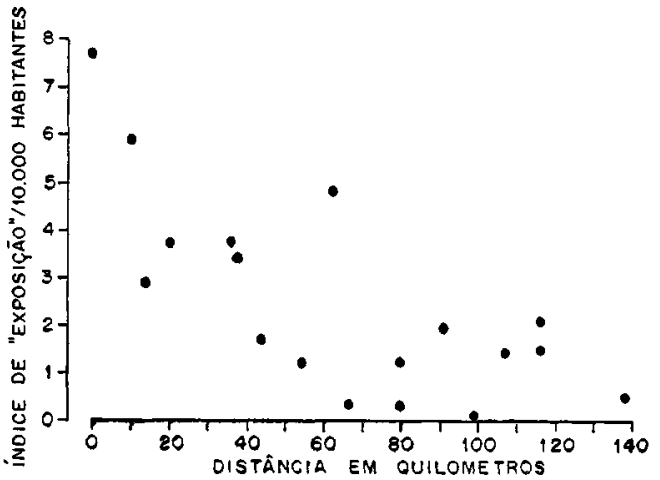

Fig. 3 - Relação entre o indice de "exposição" e a distância em quilômetros de Londrina * dos municíplos de onde vieram as pessoas consideradas expostas ao virus rábico e nas quais fol indicada a vacinação anti-rábica.

* Fonte: coleta direta no DER (Londrina). 
TORNERO, N. L. \& SHIBAYAMA, K. K. - Avaliação de um serviço de rotina (vacinação anti-rábica) no Centro de Saúde de Londrina, Paraná, Brasil. Rev. Saúde públ., S. Paulo, 8:359-67, 1974 .

T A B E L A 1

Distribuiçáo etária e por sexo das pessoas que procuraram o Centro de Saúde de Londrina, entre Junho de 1969 a abril de 1973, consideradas expostas ao vírus rábico e nas quais fol indicada a vacinação anti-rábica

\begin{tabular}{|c|c|c|c|c|c|c|}
\hline \multirow[t]{2}{*}{ Sexo } & \multicolumn{2}{|c|}{ Total } & \multicolumn{2}{|c|}{ Masculino } & \multicolumn{2}{|c|}{ Feminino } \\
\hline & N.o & $\% *$ & N.o & $\% * *$ & N.o & $\% *$ \\
\hline $01-5$ & 157 & 14,2 & 96 & 61,1 & 61 & 38,9 \\
\hline $51-10$ & 246 & 22,3 & 157 & 63,8 & 89 & 36,2 \\
\hline $10 \quad-15$ & 200 & 18,1 & 121 & 60,5 & 79 & 39,5 \\
\hline $151-20$ & 101 & 9,2 & 42 & 41,6 & 59 & 58,4 \\
\hline$\geqslant 20$ & 398 & 36,2 & 241 & 60,5 & 157 & 39,5 \\
\hline Total & 1102 & 100,0 & 657 & 59,6 & 445 & 40,4 \\
\hline
\end{tabular}

Observacáo: foram excluidos 91 casos com sexo não especificado e 69 casos de grupo etário não especificado.

* em relação ao total de casos.

** em relação ao grupo etário.

TABELA 2

Relação entre a incidência média anual por 10000 hab. e a distribuição etária e por sexo das pessoas de Londrina que procuraram o Centro de Saúde de Londrina, entre junho de 1969 a abril de 1973, consideradas expostas ao virus rábico e nas quals foi indicada a vacinação anti-rábica

\begin{tabular}{|c|c|c|c|c|c|c|}
\hline \multirow[t]{2}{*}{ Sexo } & \multicolumn{2}{|c|}{ Total } & \multicolumn{2}{|c|}{ Masculino } & \multicolumn{2}{|c|}{ Femintno } \\
\hline & N.O & Incidência & N.0 & Incidencla & N.o & Incidência \\
\hline
\end{tabular}

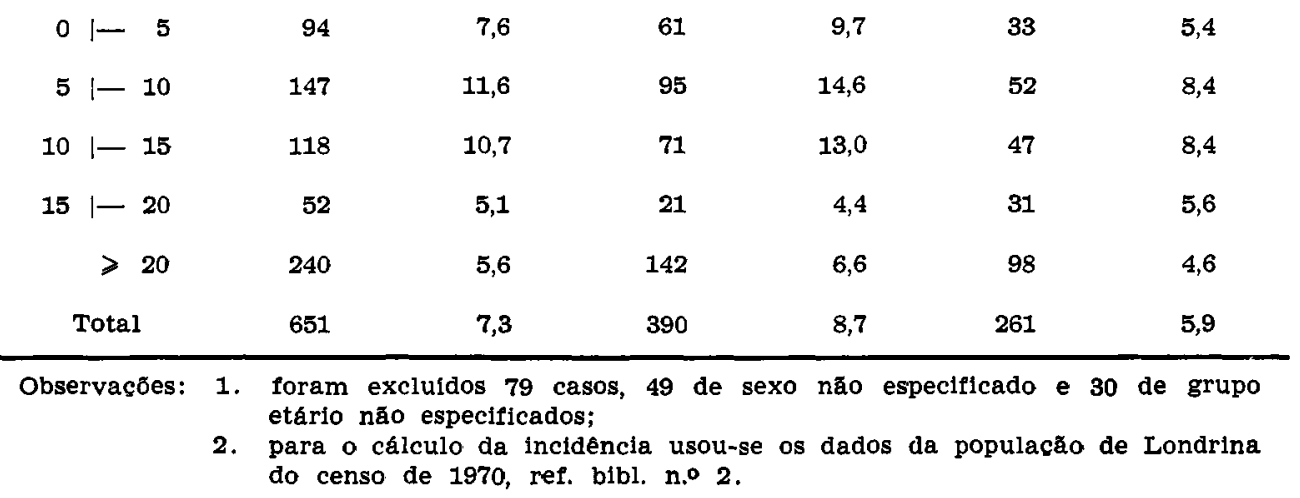


TORNERO, N. L. \& SHIBAYAMA, K. K. - Avaliação de um serviço de rotina (vacinação anti-rábica) no Centro de Saúde de Londrina, Paraná, Brasil. Rev. Saúde puibl., S. Paulo, $8: 359-67,1974$.

\section{TAB E L A 3}

Distribuição segundo o grupo etário e a procedência (autóctones e não autóctones) das pessoas que procuraram o Centro de Saúde de Londrina, entre junho de 1969 e abril de 1973 , consideradas expostas ao vírus rábico e nas quais foi indicada a vacinação anti-rábica

\begin{tabular}{|c|c|c|c|c|}
\hline \multirow{2}{*}{ Grupo etário } & \multicolumn{4}{|c|}{$P r o c e d e ̂ n c i a$} \\
\hline & Total de casos & \% Autóctones* & $\%$ Não & Autóctones * \\
\hline $01-5$ & 163 & 59,5 & & 40,5 \\
\hline $51-10$ & 258 & 60,5 & & 39,5 \\
\hline $10-15$ & 213 & 58,7 & & 41,3 \\
\hline $15 \mid-20$ & 109 & 51.4 & & 48,6 \\
\hline$\geqslant 20$ & 437 & 60,9 & & 39,1 \\
\hline Total & 1180 & 59,3 & & 40,7 \\
\hline
\end{tabular}

Observação: foram excluídos 82 casos, 74 dos quais com idade não especificada e 8 com procedência não especificada.

* Autóctones: casos do município de Londrina; não autóctones: exclui Londrina.

TABELA 4

Distribuição quanto a procedência (14,0 D.S.), frequiência e índice de "exposiçāo" por 10000 hab. das pessoas que procuraram o Centro de Saúde de Londrina, entre junho de 1969 a abril de 1973, consideradas expostas ao vírus rábico e nas quais foi indicada vacinação anti-rábica

\begin{tabular}{|c|c|c|c|}
\hline Procedência & $\begin{array}{c}\text { População } \\
\text { exposta } \times 4 *\end{array}$ & $\begin{array}{l}\text { Freqüência } \\
\text { de expostos }\end{array}$ & $\begin{array}{l}\text { fndice "de } \\
\text { exposição" }\end{array}$ \\
\hline Londrina ** & 949.716 & 730 & 7,7 \\
\hline Cambé & 142.416 & 84 & 5,9 \\
\hline Rolândia & 191.680 & 73 & 3,7 \\
\hline Sertanópolis & 87.940 & 33 & 3,7 \\
\hline Ibiporã & 108.624 & 32 & 2,9 \\
\hline Porecatú & 89.168 & 17 & 1,9 \\
\hline Bela Vista do Paraiso & 73.016 & 13 & 1,7 \\
\hline Centenário do sul & 78.232 & 12 & 1,5 \\
\hline Alvorada do Sul & 76.996 & 11 & 1,4 \\
\hline Jaguapitã & 66.912 & 8 & 1,2 \\
\hline Florestópolis & 39.092 & 5 & 1,2 \\
\hline Lupionópolis & 23.576 & 5 & 2,1 \\
\hline Mirasselva & 30.792 & 1 & 0,3 \\
\hline Guarací & 30.744 & 1 & 0,3 \\
\hline Santa Inês & 19.364 & 1 & 0,5 \\
\hline Primeiro de Maio & 103.016 & 1 & 0,1 \\
\hline Arapongas *** & 206.000 & 69 & 3,4 \\
\hline Astorga $* * *$ & 99.868 & 48 & 4,8 \\
\hline Outros municípios & - & 118 & - \\
\hline Total & - & 1262 & - \\
\hline
\end{tabular}

* Fonte: Fundação IBGE 2 .

** População estimada para 1971, com base nos censos de 1960 e 1970. Demais cidades, tomou-se os dados do censo de 1970.

*** Não pertencem ao 14.0 D.S. 
TORNERO, N. L. \& SHIBAYAMA, K. K. - Avaliação de um serviço de rotína (vacinação antí-rábica) no Centro de Saúde de Londrina, Paraná, Brasil. Rev. Saúde públ., S. Paulo, $8: 359-67,1974$.

\section{T A BEL A 5}

Distribuição das vacinas anti-rábicas prescritas as pessoas que procuraram o Centro de Saúde de Iondrina entre junho de 1969 a abril de 1973, consideradas expostas ao virus rábico e nas quais foi Indicada a vacinação anti-rábica

\begin{tabular}{c|r|r}
\hline & \multicolumn{2}{|c}{ Vacinados } \\
\cline { 2 - 3 } N.0 de doses prescritas & N.0 & $\%$ \\
\hline$<14$ & 15 & 1,3 \\
$\geqslant 14$ & 1105 & 98,7 \\
Total & 1120 & 100,0 \\
\hline
\end{tabular}

Observação: foram excluídos 142 casos cujo número de doses năo fol especificado.

tendem a ocorrer nos meses de dezembro e janeiro. A falta de outros dados não nos permitiu explicar com detalhes as causas dessas variações.

Em Ribeirão Preto ${ }^{9}$ observou-se uma média de 20 casos por mês e um aumento em agosto (média de 30). Não se observou aumento em abril, como no nosso caso. Para São Paulo não há esses dados.

Analisando-se a Tabela 1 , vemos que $59,6 \%$ dos casos ocorreram no sexo masculino. Essa porcentagem aproxima-se bastante daquelas obtidas em Ribeirão Preto $^{\circ}$ e São Paulo ${ }^{11}(55,5 \%$ e $57,2 \%$ respectivamente). Vemos também que $36,5 \%$ ocorreram em menores de 10 anos e 27,3\% dos 10 aos 19 anos. Em Ribeirão Preto ${ }^{*}$ obteve-se $38,6 \%$ e $25,2 \%$ respectivamente e em São Paulo ${ }^{11} 35,4 \%$ e $22,7 \%$ respectivamente; $54,6 \%$ dos casos ocorreram em menores de 15 anos (São Paulo ${ }^{\circ}: 50,3 \%$ ). É útil realçar a concordância dos dados entre Ribeirão Preto e os nossos, de um lado, baseados em amostras viciadas e aqueles obtidos em São Paulo, pois neste tanto os vacinados como os não vacinados foram anotados, o que permitiu conhecer-se a verdadeira demanda. Vê-se que, desde que outras variáveis não estejam influindo, as amostras por nós obtidas tendem a refletir, pelo menos quanto ao estudo do sexo e grupo etário, a verdadeira demanda. Ainda de acordo com os dados obtidos em Sáo Paulo ${ }^{9}$, a verdadeira demanda é $50,5 \%$ maior do que os casos em que foi indicada a vacinação. Voltando a Tabela 1 vemos que o sexo masculino predomina em todas as faixas etárias com exceção da faixa dos 15 aos 19 anos.

$\mathrm{Na}$ Tabela 2 estudamos, somente para o município de Londrina, a incidência de pessoas nas quais foi indicada a vacinação. Vê-se agora, usando indicadores menos sujeitos a erros, que a tendência geral da Tabela 1, para todos os casos, é confirmada. Assim a incidência é maior no sexo masculino e, neste sexo, em todas as faixas etárias, exceção dos 15 aos 19 anos.

Pela Tabela 3 vemos que $59,3 \%$ dos casos são autóctones. Neste particular os nossos dados diferem daqueles obtidos em Ribeirão Preto e São Paulo $(88,9 \%$ e $77,7 \%$ respectivamente) ${ }^{9,11}$. Pelos dados atuais não nos é possível explicar tais diferenças.

Na Tabela 4, relacionamos a procedência de todos os casos e calculamos um índice de "exposição" por 10.000 habitantes baseado no número de casos no período estudado e o número de indivíduos teoricamente expostos no mesmo período. Quatro municípios pertencentes ao 14..$^{\circ}$ Distrito Sanitário não estão ai relacionados, pois neles nenhum caso foi relatado (Nossa Senhora das Graças, Cafeara, Santo Inácio e Colorado). Achamos útil incluir dois municpios que não pertencem ao $14 .^{\circ}$ Distrito Sanitário (Arapongas e Astorga) mas que constribuiram com um número importante de pessoas. Provêm do $14 .^{\circ}$ Distrito Sanitário $81,3 \%$ das pessoas, incluindo-se as duas cidades citadas, essa porcentagem vai a $91,0 \%$. Os $9,0 \%$ restantes, catalogados como "outros municípios", incluem uma varie- 
TORNERO, N. L. \& SHIBAYAMA, K. K. - Avaliação de um serviço de rotina (vacinaçâo. anti-rábica) no Centro de Saúde de Londrina, Paraná, Brasil. Rev. Saúde públ., S. Paulo, 8:359-67, 1974 .

dade deles, alguns próximos, outros afastados de Londrina.

Nas figuras 2 e 3 relacionamos o índice de "exposição" por 10.000 habitantes com a porcentagem de urbanização e com a distância em quilômetros de Londrina dos municípios constantes na Tabela 4. Vê-se, pela Figura 2, que o índice e a porcentagem de urbanização estão diretamente relacionados e que, pela Figura 3, a medida que a distância de Londrina aumenta, os índices tendem a cair. Calculando-se o coeficiente de correlação de Spearman entre o índice de "exposição" e a distância e o índice de "exposição" e a porcentagem de urbanização, obtivemos respectivamente $r_{\mathrm{s}}=0,636$ e $r_{\mathrm{s}}=0,634$, significantes ao nível de $1 \%$. Logo, esses dois fatores - urbanização e distância de Londrina - mostram ter relação com a vinda de expostos a Londrina, porém há necessidade de chamar-se a atenção para um $3 .^{\circ}$ fator, que é a polarização de outros centros sobre determinados municípios. Os quatro municípios de onde não vieram pessoas consideradas expostas ficam no mínimo a $100 \mathrm{Km}$ de Londrina (variação de 100 a $136 \mathrm{Km}$ ) e têm baixa porcentagem de urbanização (22 a $31 \%$ ); com esses dados esperar-se-ia baixo índice de "exposição". Porém, esses 4 municípios (juntamente com Sta. Ines, com um caso no período) estão em uma região bem definida à noroeste de Londrina, próximos ao Estado de São Paulo. Isso faznos sugerir a hipótese de que cidades do Estado de São Paulo podem estar polarizando à atenção médica desses municípios. Julgamos fundamental para um planejamento racional de saúde, em qualquer lugar, a exata caracterização de um fato como este.

A Tabela 5 mostra-nos que para $98,7 \%$ das pessoas em que foi indicada a vacinação, foram prescritas no mínimo 14 doses. Esta alta porcentagem observa-se também em Ribeirão Preto ${ }^{\circ}(80,0 \%)$ e em São Paulo ${ }^{11}(80,7 \%)$. Se todas as pessoas cumpriram o esquema proposto não sabemos, mas acredita-se, empiricamente, que o abandono seja pequeno, devido ao medo da doença pela população (em Ribeirão Preto o abandono foi de $1,8 \%)$. Vê-se que rotineiramente são prescritas 14 doses. A esse respeito nos reportamos ao trabalho de HeLd et al. ${ }^{5}$ (1972) que descrevem a experiência de vacinação em uma região argentina com um esquema simplificado, desde 1965, de vacina semelhante à usada entre nós. Nesse esquema argentino, as doses prescritas variam entre 3,7 e 14 (mais 2 reforços em todos os casos), conforme as circunstâncias do ferimento, sendo que a maioria dos expostos recebe o $1 .^{\circ}$ ou 0 2. ${ }^{\circ}$ esquema. Segundo esses autores, o esquema é altamente eficaz, sendo eficiente o nível de anticorpos alcançado. Entre nós, vários experimentos usando esquemas simplificados foram publicados ${ }^{3,7,8}$ visando principalmente a vacinação preventiva e em todos eles o nível de anticorpos alcançado foi altamente eficaz.

Os acidentes neurológicos com a vacina tipo Fuenzalida, ou modificadas, são considerados raros. Held \& Adaros * (1972), fazendo um levantamento do número de pessoas vacinadas nas Américas com essa vacina, de 1963 a 1968, encontraram, para 510.500 pessoas vacinadas foram anotados 32 casos de doenças neurológicas atribuídas à vacinação (casos registrados de janeiro de 1964 a outubro de 1969). Não se observou nenhum acidente com menos de 5 doses.

Sugerimos, pois, o estudo de um esquema simplificado de vacinação. As vantagens imediatas seriam: a) maior facilidade ao paciente, principalmente aqueles que moram em zona rural, pequenas localidades ou que têm dificuldade para tomar a vacina (nos centros de Saúde, farmácias, etc.); b) menor custo.

A prevalência da doença em animais é ignorada. Quanto a casos humanos, no 
TORNERO, N. L. \& SHIBAYAMA, K, K. - Avaliação de um serviço de rotina (vacinação anti-rábica) no Centro de Saúde de Londrina, Paraná, Brasil. Rev. Saúde pübl., S. Paulo, 8:359-67, 1974 .

período estudado, tomamos conhecimento de dois, ambos fatais, ocorridos em crianças não vacinadas.

Finalmente. chamamos a atenção para o fato de que a análise desses dados não deve ser esporádica, mas sim contínua, para que os reajustes necessários sejam feitos na época oportuna. Para isso há necessidade de uma melhor padronização das informações a serem obtidas e em menor número possível. Coletas abundantes de dados devem ser deixadas para trabalhos de pesquisa, como já citado ${ }^{11}$. Sugerimos também que a análise rotineira das informações seja feita pelo próprio funcionário que as coleta, integrando-o assim ativamente à equipe de saúde $\mathrm{e}$ dando-lhe oportunidade de compreender melhor a importância do serviço que executa e sugerir mudanças que poderão ser úteis.

\section{CONCLUSOES}

Pela análise do material, concluimos que:

1) o maior número de pessoas que se julgaram expostas ao vírus e nas quais foi lhes indicada vacinação, pertencem ao sexo masculino; isto ocorre em todas as faixas etárias. com exceção dos 15 aos 19 anos onde há predominância do sexo feminino;

2) o estudo da incidência de pessoas julgadas expostas para o município de Londrina, particularmente, também concordam com os achados acima;

$3)$ nossos dados, mesmo não refletindo a verdadeira demanda ao serviço. concordam com algumas informações (sexo e grupo etário) obtidas em trabalhos que refletem a verdadeira magnitude dessa demanda, o que reforça a idéia de que informações julgadas incompletas não devem ser desprezadas totalmente quando se busca dados para planejamento;

4) os casos autóctones predominam sobre os não autóctones;

5) existe uma correlação entre o índice de "exposição" ao vírus rábico e a urbanização e a distância do município considerado em relação a Londrina:

6) rotineiramente são prescritas 14 doses de vacina para os casos julgados expostos;

7) há necessidade de uma análise contínua das informaçōes coletadas para que reajustes necessários na melhoria da eficiência do serviço sejam feitos na época oportuna. Para melhor integração do funcionário ao serviço que executa e também para maior aproveitamento dos recursos humanos, essa análise deve ser feita pelo funcionário que coleta essas informações.

\section{A G R A D E I M E N T OS}

Aos colegas D. A. Soares, J. L. Nogueira, M. T. T. Tornero e N. R. Santos pelas sugestōes; ao Dr. J. D. Ayres, Chefe do $14 .^{\circ}$ Distrito Sanitário, pelas facilidades que nos ofereceu na coleta dos dados. 
TORNERO, N. L. \& SHIBAYAMA, K. K. - Avaliação de um serviço de rotina (vacinação anti-rábica) no Centro de Saúde de Londrina, Paraná, Brasil. Rev. Saúde públ., S. Paulo, 8:359-67, 1974 .

TORNero, N. L. \& ShIBAyAMA, K. K. - [A rotine service evaluation (antirabies vaccination) in the Londrina, Paraná, Brazil.] Rev. Saúde públ., S. Paulo, 8:359-67, 1974 .

SUMMARY: The importance of continued analysis of information routinely obtained in health services so that necessary readjustments at the right time may be made by allowing such information to be used in scientifical planning, thus improving efficiency, is here discussed. An antirabic vaccination service in a Health Center was chosen for evaluation. The population studied was that which turned up at the service at the time of the present study (June 1969 to April 1973). The influence of urbanization and the distance from the main town on the flow of people towards the service were analysed as well as the schedules employed for antirabic vaccination. As much as possible the authors compared the data obtained with those of other services and concluded that the differences discovered were not significant.

UNITERMS: Health Center*; Service of routine (evaluation)*; Sanitary information system *.

\section{REFERENCIAS BIBLIOGRAFICAS}

1. ALDERSON, M.R. - Sistemas de información sanitária. Crón. OMS, 28: $57-9,1974$.

2. FUNDAÇA INSTITUTO BRASILEIRO DE GEOGRAFIA E ESTATISTICA Censo demográfico: Paraná. Rio de Janeiro, 1970. Recenseamento geral, 8.0, 1970. (Série regional).

3. GODOY, A.M. - Estudios de anticuerpos antirrabicos formados en personas inmunizadas con vacuna de cerebro de ratón lactante. I. Esquemas de vacunacion con número reducido de doses con y sin immunizacion de refuerzo. Arq. Esc. Vet., Belo Horizonte, 19:121-8, 1967.

4. HELD, J.R. \& ADAROS, H.L. - Neurological disease in man following administration of suckling mouse brain antirabies vaccine. Bull. Wld. Hlth. Org., 46:321-7, 1972 .

5. HELD, J.R. et al. - Inmunizacion humana con vacuna antirrabica de cerebro de ratón lactante. Bol. Ofic. sanit. panamer, $72: 565-75,1972$.

6. HILLEBOE, H.E. et al. - Metodos de planificacion sanitaria nacional. Ginebra, Organizacion Mundial de la Salud, 1973. (Cuadernos de salud publica, 46).
7. MARKUS, H.L, et al. - Vacina antirabica tipo "Fuenzalida" modificada: cinco anos de produção e observaçōes. Rev. Inst. Med. trop. S. Paulo, 13:114-20, 1971.

8. MOREIRA, E.C. et al. - Inmunizacion preventiva contra la rabia humana. Bol. Ofic. sanit. panamer., 73:110-6. 1972 .

9. NOGUEIRA, J.L. et al. - Controle de casos na prevenção da raiva: estudo de dados registrados pelo Centro de Saúde de Ribeirāo Preto, 1960/1969. In: CONGRESSO BRASILEIRO DE HIGIENE, 18. , São Paulo, 1970. Resumo dos trabalhos. São Paulo, 1970. p. 98 .

10. PARANA. Secretaria de Saúde Pública. Departamento de Unidades Sanitárias. Portaria $149 / 70$.

11. RIBEIRO NETO, A. \& MACHADO, C.G. - Alguns aspectos epidemiológicos da exposição humana ao risco da infecção pelo vírus da raiva na cidade de São Paulo (Brasil), Rev. Inst. Med. trop. S. Paulo, 12:16-30, 1970.

Recebido para publicação em 2/ 9/1974 A provado para publicacão em 4/10/1974 